\title{
Analysis of a Hybrid Wing Body Center Section Test Article
}

\author{
Hsi-Yung T. Wu ${ }^{1}$ and Peter Shaw ${ }^{2}$ \\ Boeing Research \& Technology, The Boeing Company, Seal Beach, CA 90740 \\ and \\ Adam Przekop ${ }^{3}$ \\ Analytical Mechanics Associates, Inc., Hampton, VA 23666
}

\begin{abstract}
The hybrid wing body center section test article is an all-composite structure made of crown, floor, keel, bulkhead, and rib panels utilizing the Pultruded Rod Stitched Efficient Unitized Structure (PRSEUS) design concept. The primary goal of this test article is to prove that PRSEUS components are capable of carrying combined loads that are representative of a hybrid wing body pressure cabin design regime. This paper summarizes the analytical approach, analysis results, and failure predictions of the test article. A global finite element model of composite panels, metallic fittings, mechanical fasteners, and the Combined Loads Test System (COLTS) test fixture was used to conduct linear structural strength and stability analyses to validate the specimen under the most critical combination of bending and pressure loading conditions found in the hybrid wing body pressure cabin. Local detail analyses were also performed at locations with high stress concentrations, at Tee-cap noodle interfaces with surrounding laminates, and at fastener locations with high bearing/bypass loads. Failure predictions for different composite and metallic failure modes were made, and nonlinear analyses were also performed to study the structural response of the test article under combined bending and pressure loading. This large-scale specimen test will be conducted at the COLTS facility at the NASA Langley Research Center.
\end{abstract}

\section{Introduction}

Structural design and analysis of an 80\%-scale hybrid wing body (HWB) center section test article were recently completed. ${ }^{[1-4]}$ This test article is approximately 30 -foot long, by 14 -foot tall, and 7-foot deep. The exterior shell and floor are comprised of eleven Pultruded Rod

1 Associate Technical Fellow, The Boeing Company, MC 110-SK56, 2600 Westminster Blvd, Seal Beach, CA 90740-5600.

2 Senior Analysis Engineer, The Boeing Company, MC 110-SK56, 2600 Westminster Blvd, Seal Beach, CA 90740-5600.

${ }^{3}$ Engineer 5, c/o NASA Langley Research Center, Mail Stop 190, 8 West Taylor Street, Hampton, VA 23681-2199, Senior Member AIAA. 
Stitched Efficient Unitized Structure (PRSEUS) panels, and the interior ribs are four composite sandwich panels. As shown in Figure 1, the test article has one crown, one floor, one center keel, two side keels (left and right), two upper bulkheads (forward and aft), two lower bulkheads (forward and aft), and two outer ribs (left and right) made of PRSEUS, and two upper center ribs (left and right) and two lower center ribs (left and right) made of sandwich structures. All of the composite panels are mechanically joined at the edges by metallic fittings and fasteners. The design, analysis, and manufacturing of this test article are performed by The Boeing Company and funded by The National Aeronautics and Space Administration's (NASA's) Environmentally Responsible Aviation (ERA) Program. The manufacturing of these PRSEUS composite panels and assembly of the test article are currently ongoing at The Boeing Huntington Beach facilities. Once the test article is assembled, it will be delivered to the Combined Loads Test System (COLTS) facility ${ }^{[5]}$ at the NASA Langley Research Center for a series of structural validation experiments.

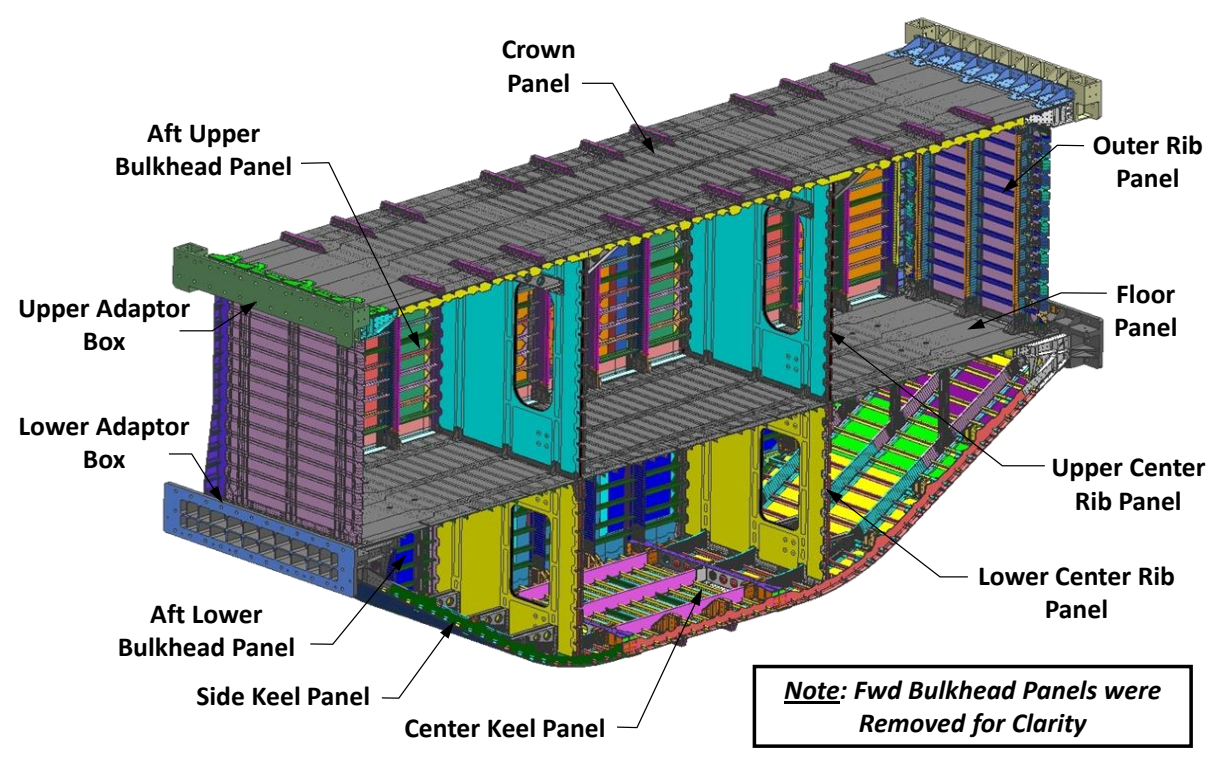

Figure 1. Hybrid Wing Body Center Section Test Article

In order to close the design on the HWB with a light-weight, cost-effective, manufacturable concept, a PRSEUS configuration, shown in Figure 2, was selected. Throughout the ERA Phase I, NASA and Boeing engineers have developed fundamental PRSEUS technologies to meet the challenging HWB center body design requirements. The PRSEUS panel is a onepiece composite structure made of dry warp-knit fabrics, pre-cured rods, and foam-core materials that are stitched and assembled together to create a unique stiffened panel geometry and then infused with Hexcel's HexFlow VRM 34 resin and co-cured without the use of Inner Mold Line (IML) tools or an autoclave. The dry warp-knit fabrics, which are used on the skins, stringers, and frames, are composed of layers of graphite material forms that are pre-knit into multi-ply stacks of standard-modulus fibers. Each stack has a nominal cured thickness of 0.052 inch and with a (44/44/12) fiber architecture, where the values are percentages of $(0 / \pm 45 / 90)$ degree plies. In the current HWB cabin design, the 0-degree plies of the stringer and frame stacks are aligned along their length-directions, and the 0-degree plies of the skin stacks are parallel to the frames' direction. 


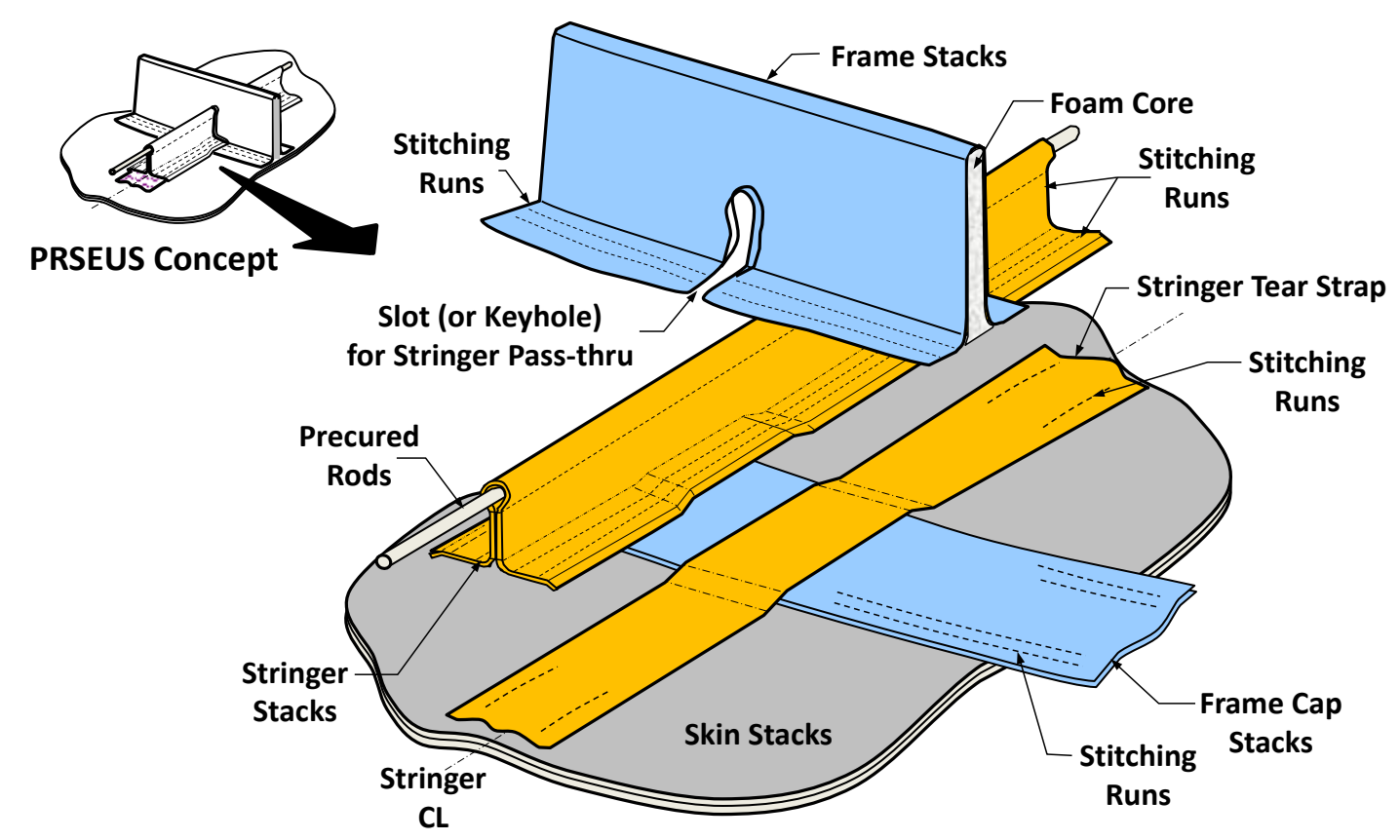

Figure 2. Exploded View of Pultruded Rod Stitched Efficient Unitized Structure (PRSEUS) Concept

Stringer and frame dimensions of the HWB center section test article are shown in Figures 3 and 4. On the stringer member, a precured pultruded rod, made of Toray unidirectional T800 fibers with a 3900-2B resin, is inserted between two folded stringer stacks at the top of the stringer web to form a stringer cap. The stringers are 1.65 inches tall and have a nominal stringer spacing of 6 inches. On the frame member, a Rohacell foam-core is wrapped by the frame stacks to form a sandwich structure. At locations where frames are connected to metallic fittings by fasteners, fiberglass-cores replace the foam-cores for their higher bolt bearing load capability. The frames are 6 inches tall and have a nominal frame spacing of 24 inches. Multiple stacks of the warp-knit material can be used to build up the desired part stiffness, strength, and configuration. The flanges of the stringer and frame are stitched to the skin using stitching threads made of Vectran fibers. These stitching threads provide additional benefit on damage arresting capability which allows the PRSEUS configuration to operate at higher strain levels and further into the post-buckled design regime. Load path continuity at the stringer-frame intersection is maintained in both directions by passing the rod-stringer section through a slot (or keyhole) on the frame (Figure 2). In the ERA Phase I study, the PRSEUS panel demonstrated its superior structural performance over traditional stiffened panel and sandwich concepts. ${ }^{[6]}$ Based on the results of these trade studies, it is also believed that the PRSEUS design concept can be used not only on flat-sided panels, but also on structures such as a circular fuselage barrel or a higher aspect ratio wing to reduce airframe weight. 


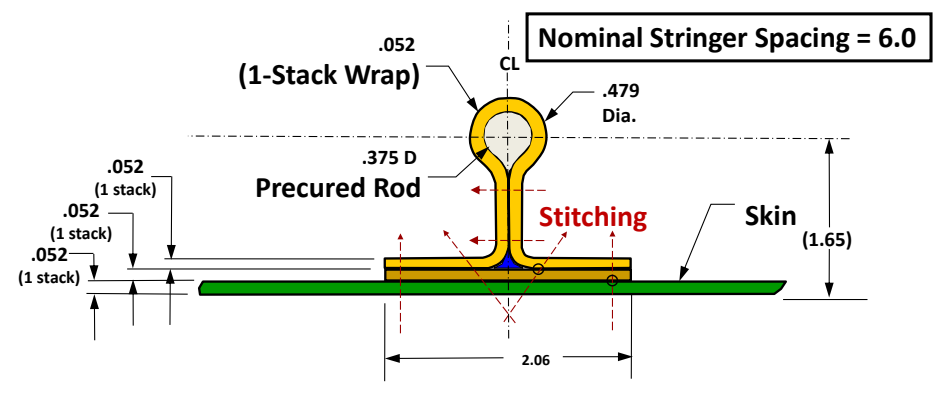

Figure 3. Stringer Dimensions (inches) of the HWB Center Section Test Article

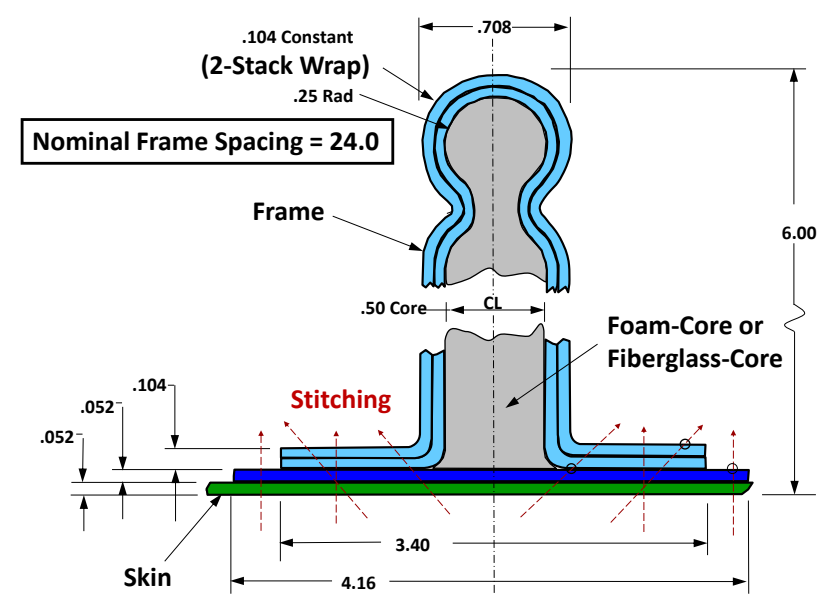

Figure 4. Frame Dimensions (inches) of the HWB Center Section Test Article

During the HWB airframe development activities in the NASA ERA Phase I project, ${ }^{[6-10]}$ the PRSEUS structural concept was able to demonstrate its exceptional damage arresting capability and efficiently reacting loads in each of the three primary loading directions. ${ }^{\text {[11-13] }}$ These three primary directions are stream-wise loading (Nx), span-wise loading (Ny), and internal pressure (Nz) directions (Figure 5). On an HWB cabin made of PRSEUS panels, the wing bending loads are carried by the frame members, and the fuselage bending loads are carried by the stringers. A key aspect of this test article approach is the validation of the structural performance in a combined loading environment where the axial loads ( $\mathrm{Nx}$ and $\mathrm{Ny}$ ) were combined with internal pressure loading $(\mathrm{Nz})$ that are representative of the design regimes of the HWB pressure cabin. 


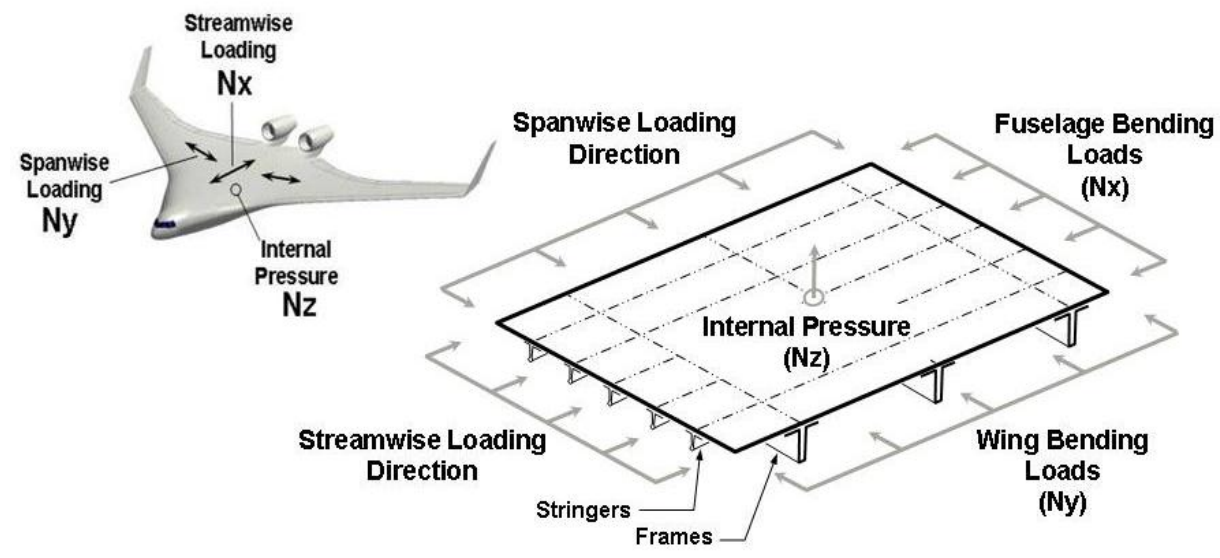

Figure 5. HWB Pressure Cabin Crown Panel Loading

The main objective of the HWB center section test article is to demonstrate that it is possible to meet the demanding HWB structural design requirements inherent to designing an internally-pressurized, flat-sided pressure cabin that is also simultaneously loaded in bending. To better understand the risk that a flat-sided HWB pressure cabin design may come across in pressure loading, the smaller scale cube specimen shown in Figure 6 was built. This pressure cube was successfully tested in 2010 up to the internal pressure of $5.22 \mathrm{P}$ or $48 \mathrm{psi}^{[14]}$ where the nominal pressure $1 \mathrm{P}$ of $9.2 \mathrm{psi}$ is dictated by the intended cruise altitude. Similar to the HWB center section test article, the pressure cube consisted of crown, floor, bulkhead, and rib structures made of PRSEUS panels. The success of the pressure cube test validated the structural joint design concept between PRSEUS panels using metallic fittings and fasteners, as well as providing design values to support the larger scale analysis and test.

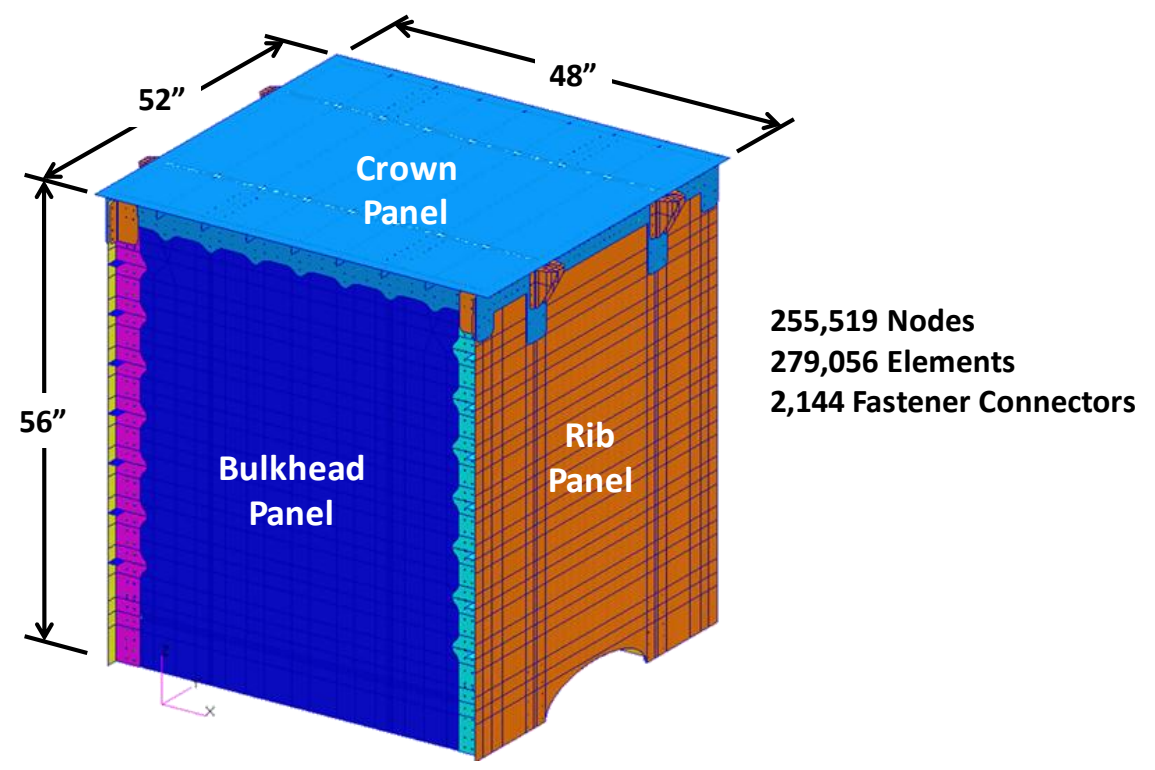

Figure 6. Finite Element Model of the Pressure Cube Test Article 


\section{Analytical Approach of the Test Article}

The test article geometry was derived from a typical HWB center body section and the structural sizing was based on a simplified subset of maneuver, taxi bump, and cabin pressure loading conditions. ${ }^{[15,16]}$ The most critical load cases for the test specimen were the $2 \mathrm{P}$ static pressure, the 2.5-g up-bending maneuver, and the $-1.0-\mathrm{g}$ down-bending maneuver. In addition to the maneuver-induced loading, these conditions were also considered with, and without, internal cabin pressure; resulting in additional load cases of combined maneuverplus-pressure loading. Whereas the $2 \mathrm{P}$ load case (18.4 psi) is a true design ultimate load (DUL) condition, the 2.5 -g and $-1.0-\mathrm{g}$ maneuver load cases are only design limit load (DLL) conditions and must be multiplied by a 1.5 factor-of-safety to achieve the final DUL design state. Note that this factor of safety was also applied to the internal pressure loading component of the combined condition. These five critical loading conditions were used in sizing the test article and they will be used as the test loads at the NASA COLTS test facility.

The analysis methodology used to assess the test article was based on the analyses and experiments conducted under prior PRSEUS research programs using a conventional building-block approach (Figure 7). Lessons learned from previous PRSEUS coupons, panels, and pressure cube studies were implemented on this test article. The structural sizing of this test article was determined by linear analyses using MSC NASTRAN. ${ }^{[1]}$ Linear structural strength and stability analyses were performed using the five most critical loading conditions found in the HWB center section. Nonlinear behaviors of the test article, such as the post-buckling of the skin under compressive loading and the nonlinear structural response in combined maneuver-and-pressure loading, were not included in the initial sizing of the test article. In addition to the linear assessment, a geometric nonlinear analysis is being performed by personnel at the NASA Langley Research Center using the same global finite element (FE) model that was used for the linear analyses. Some of the preliminary results from the nonlinear analysis for the $2 \mathrm{P}$ loading condition are included in this paper. In addition to the $2 \mathrm{P}$ loading condition, more result comparisons between linear and nonlinear structural responses will be performed for the maneuver and combined maneuver-andpressure loading conditions. 


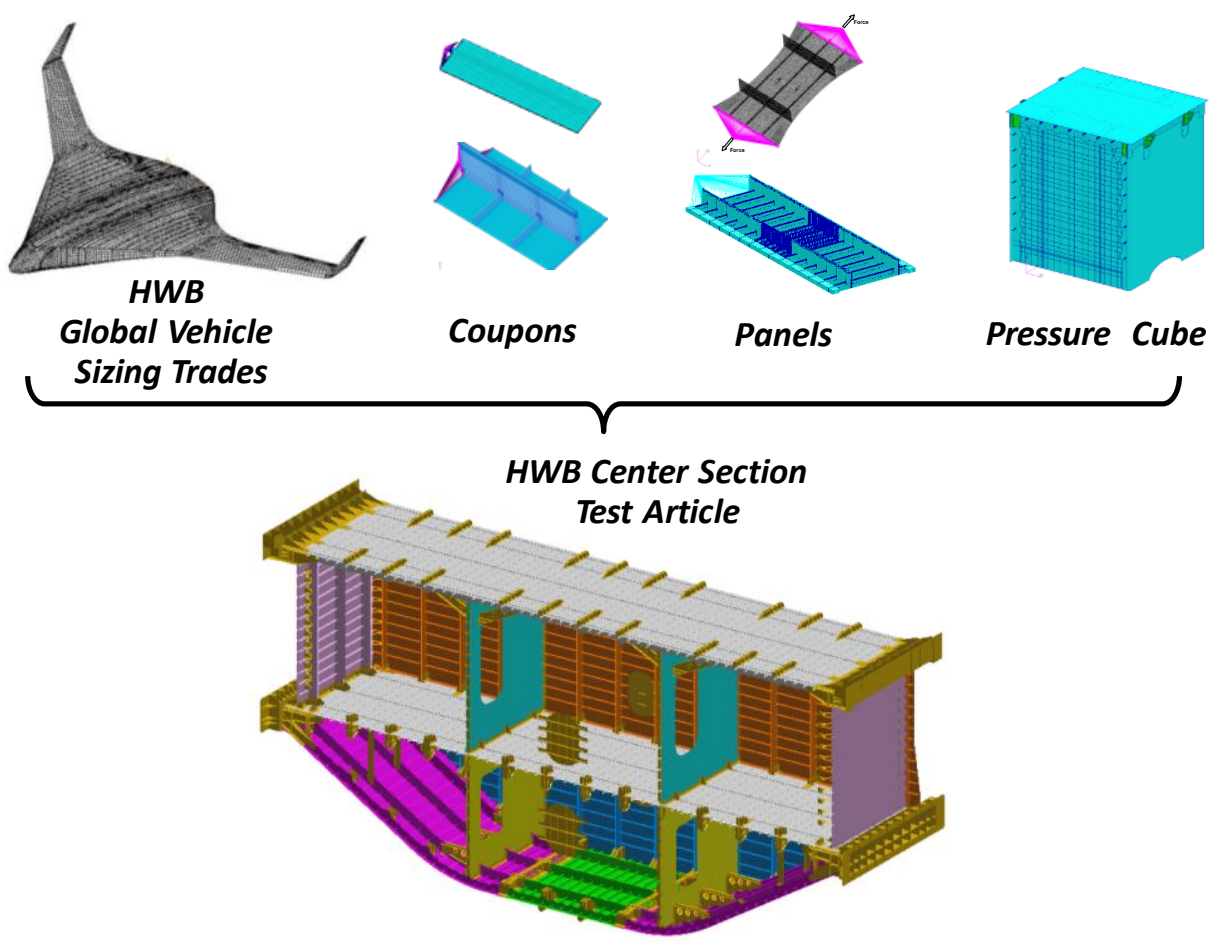

Figure 7. Building-Block Approach of the HWB Center Section Test Article

The primary goal of the test article is to prove that PRSEUS, especially the panels with minimum-gage thickness (1-stack or 0.052 inch), are capable of carrying the most critical combined maneuver-and-pressure loads that an HWB pressure cabin will encounter. To demonstrate this load-carrying capability, some areas on the test article were specifically designed with the minimum-gage skin thickness for the experiment. These minimum gage testing regions were located at the center sections of the crown, floor, keel, bulkhead, and outer rib panels. Other structures, such as the metallic fittings and fasteners, were designed to provide structural support to these testing regions. Neither a comprehensive structural weight optimization nor a fatigue analysis was performed on these structures in order to save the test article's development costs. Although the metallic fittings and fasteners were not fully optimized for weight saving, they represent the most feasible fitting designs and fastener load paths for the final test article design.

\section{Global Finite Element Analysis}

In order to obtain the internal loads for the structural sizing study, a global FE model was constructed (Figure 8). The model contains 1-D and 2-D elements for the composite and metallic structures. Sufficient structural detail and mesh density are included in this model for accurate internal load calculations. In this global FE model, layered composite plate elements were used to model the composite members such as skin, Tee-cap web, stringer web, and frame web. In addition, bar elements were used to model the caps of frames and the pultruded rods on the stringers. Isotropic plate elements were used to model the flanges and webs on the metallic fittings, and fastener elements were used to model the mechanical fasteners. 
For the COLTS loading and reacting platens, isotropic plate elements were used to model the mounting plates, and bar elements were used to model the backing truss beams. Boundary constraints were applied on the COLTS FE model at the supporting locations to the ground. The actuator connecting points on the COLTS loading and reacting platens were used as the axial load introduction points to simulate the up-bending (2.5-g) and the down-bending (-1.0g) maneuver loads on the test article. With an element size of approximately one-inch, this global FE model contains more than four million degrees of freedom.

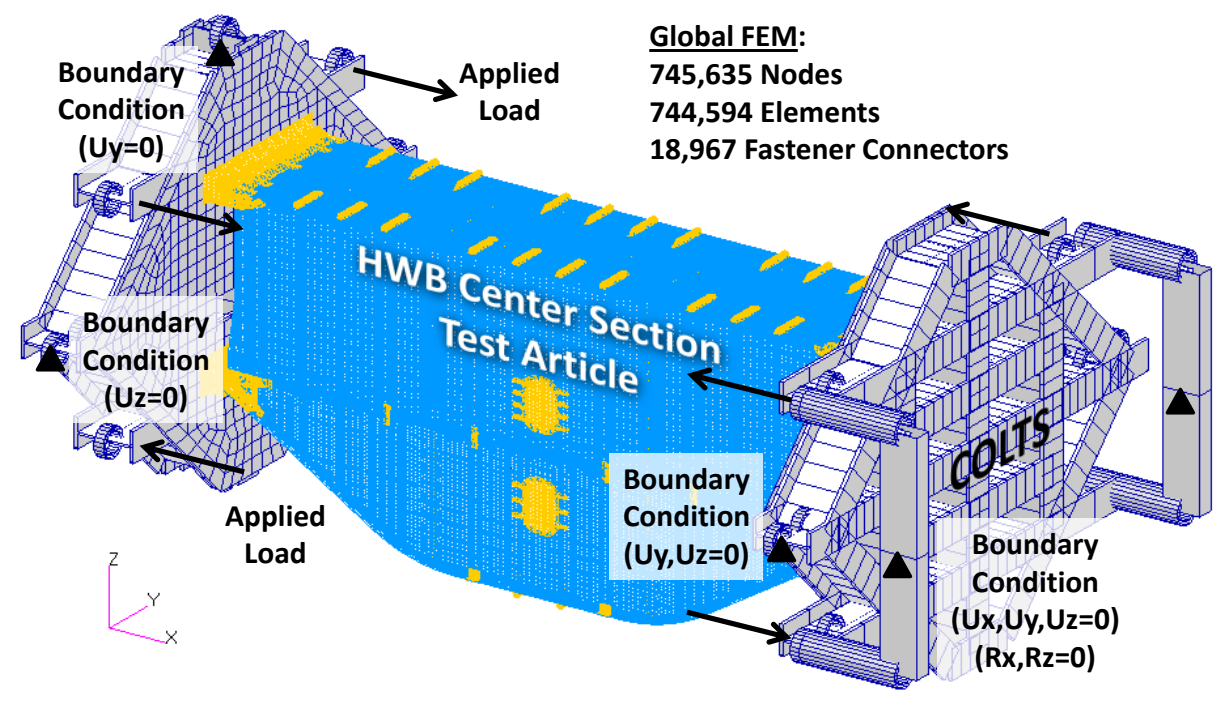

Figure 8. Finite Element Model of the Test Article and COLTS Test Fixture

The material properties of the test article, such as the moduli and the design values, are listed in Tables 1 and 2. This global FE model was used in the linear static, linear buckling, and geometrically nonlinear static analyses. Structural results at DUL, such as element forces, stresses, and strains of each structural component, were calculated using a finite element analysis (FEA) and compared with material design values for margin of safety calculations and failure predictions. For example, at fastener locations, forces on bolts were extracted from the FEA and checked with fastener-related failure modes, such as bolt axial failure in tension, bolt shear failure, composite/metallic panel pull-through failure, and composite/metallic panel bearing failure. For the metallic fittings, von Mises stresses were compared with metallic tensile yield design values. No yielding was allowed on metallic fittings at DUL in the linear analysis. For the composite structures, maximum and minimum principal strains were compared with the notched composite design values to calculate margins of safety at DUL. 
Table 1. Composite and Metallic Material Moduli of the Test Article

\begin{tabular}{|c|c|c|c|c|c|c|c|}
\hline \multirow{2}{*}{ Material } & \multicolumn{4}{|c|}{ Composite } & \multicolumn{3}{c|}{ Isotropic } \\
\cline { 2 - 8 } & $\begin{array}{c}\text { E11 } \\
\text { (Msi) }\end{array}$ & $\begin{array}{c}\text { E22 } \\
(\mathbf{M s i})\end{array}$ & $\mathbf{v 1 2}$ & $\begin{array}{c}\text { G12 } \\
(\mathbf{M s i})\end{array}$ & $\begin{array}{c}\text { E } \\
(\mathbf{M s i})\end{array}$ & $\mathbf{v}$ & $\begin{array}{c}\mathbf{G} \\
\text { (ksi) }\end{array}$ \\
\hline Composite Laminate (1-Stack) & 9.74 & 4.865 & 0.4 & 2.37 & n.a. & n.a. & n.a. \\
\hline Stringer Rod & n.a. & n.a. & n.a. & n.a. & 20.1 & 0.3 & n.a. \\
\hline Frame Foam-Core & n.a. & n.a. & n.a. & n.a. & 0.01882 & n.a. & 7.25 \\
\hline Frame Fiberglass-Core & n.a. & n.a. & n.a. & n.a. & 1.7 & 0.3 & n.a. \\
\hline Aluminum Fitting & n.a. & n.a. & n.a. & n.a. & 10.3 & 0.33 & n.a. \\
\hline Titanium Fastener & n.a. & n.a. & n.a. & n.a. & 16.9 & 0.31 & n.a. \\
\hline
\end{tabular}

Table 2. Composite and Metallic Material Design Values of the Test Article

\begin{tabular}{|c|c|c|c|c|}
\hline Design Regions & Loading Type & \begin{tabular}{|c|} 
Notched \\
Design Values \\
(micro-in/in) \\
\end{tabular} & \begin{tabular}{|c|} 
Un-notched \\
Design Values \\
(micro-in/in) \\
\end{tabular} & \begin{tabular}{|c|} 
Strength \\
Design Values \\
(psi) \\
\end{tabular} \\
\hline \multirow{2}{*}{ Skin } & Compression & $-4,800$ & $-8,000$ & n.a. \\
\hline & Tension & 5,900 & 10,000 & n.a. \\
\hline \multirow{2}{*}{$\begin{array}{l}\text { Stringer } \\
\text { Web }\end{array}$} & Compression & $-5,800$ & $-8,000$ & n.a. \\
\hline & Tension & 7,000 & 10,000 & n.a. \\
\hline \multirow{2}{*}{$\begin{array}{l}\text { Stringer } \\
\text { Flange }\end{array}$} & Compression & $-4,800$ & $-8,000$ & n.a. \\
\hline & Tension & 5,900 & 10,000 & n.a. \\
\hline \multirow{2}{*}{$\begin{array}{c}\text { Frame \& Tee-cap } \\
\text { Web }\end{array}$} & Compression & $-5,800$ & $-8,000$ & n.a. \\
\hline & Tension & 7,000 & 10,000 & n.a. \\
\hline \multirow{2}{*}{$\begin{array}{c}\text { Frame \& Tee-cap } \\
\text { Flange }\end{array}$} & Compression & $-4,800$ & $-8,000$ & n.a. \\
\hline & Tension & 5,900 & 10,000 & n.a. \\
\hline Inter-laminar & Tension & n.a. & n.a. & 6,452 \\
\hline \multirow{3}{*}{$\begin{array}{c}\text { Foam Core } \\
\text { Rohacell 110WF }\end{array}$} & Compression & n.a. & n.a. & 319 \\
\hline & Tension & n.a. & n.a. & 441 \\
\hline & Shear & n.a. & n.a. & 253 \\
\hline \multirow{2}{*}{$\begin{array}{c}\text { Fiberglass } \\
\text { Garolite G-11 }\end{array}$} & Compression & n.a. & n.a. & 32,900 \\
\hline & Tension & n.a. & n.a. & 37,000 \\
\hline $\begin{array}{c}\text { Aluminum Fitting } \\
\text { (Strength Study) }\end{array}$ & $\begin{array}{c}\text { Tension } \\
\text { (Yielding) } \\
\end{array}$ & n.a. & n.a. & $\begin{array}{c}41,000 \\
\text { to } 70,000^{*} \\
\end{array}$ \\
\hline \multirow{2}{*}{$\begin{array}{c}\text { Aluminum Fitting } \\
\text { (Fastener Study) }\end{array}$} & Bearing & n.a. & n.a. & 105,000 \\
\hline & Pull-through & n.a. & n.a. & 48,000 \\
\hline \multirow{2}{*}{$\begin{array}{l}\text { Composite Panel } \\
\text { (Fastener Study) }\end{array}$} & Bearing & n.a. & n.a. & 70,000 \\
\hline & Pull-through & n.a. & n.a. & 5,230 \\
\hline \multirow{2}{*}{$\begin{array}{c}\text { Titanium Fastener } \\
\text { (Fastener Study) }\end{array}$} & Tension & n.a. & n.a. & 160,000 \\
\hline & Shear & n.a. & n.a. & 95,000 \\
\hline
\end{tabular}

Note: *Aluminum fitting materials are 7050-T7451, 7075-T6, and 7075-T651.

Their tensile yielding allowables depend on material types and stock sizes. 
In the linear FEA of the global model, the results from margin of safety calculations showed that all of the composite structures, metallic fittings, and fasteners had positive margins of safety in all DUL conditions. For the composite structures, the highest strain values were seen at the skin and stringer webs on the crown, center keel, and upper bulkhead panels. Among these critical locations with the high strain values, there were a total of six locations with margins of safety lower than $10 \%$, and the lowest margin of safety was $2 \%$ on the crown panel stringer web in the 2P DUL condition (Figure 9). For the metallic fittings, there were five fittings with margins of safety lower than $10 \%$, and the lowest margin of safety was $1.7 \%$ on the fitting that is connecting to the lower bulkhead and side keel in the 2P DUL condition (Figure 10). For the fastener failure checks, the lowest margin of safety was $4 \%$ with the composite bearing failure on the floor panel at the location where the floor and lower bulkhead were joined together by metallic fittings in the 2P DUL condition.

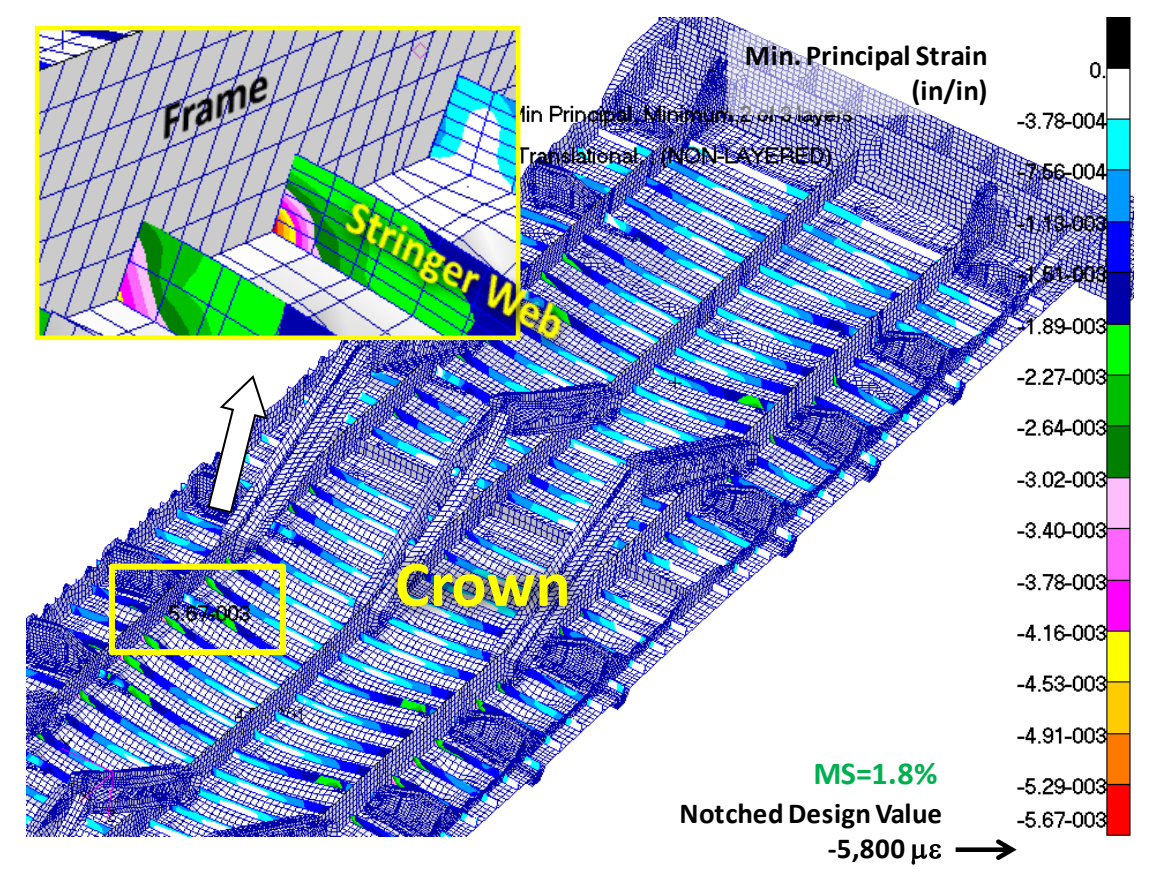

Figure 9. Minimum Principal Strain on Crown Stringer Web in the 2P DUL 


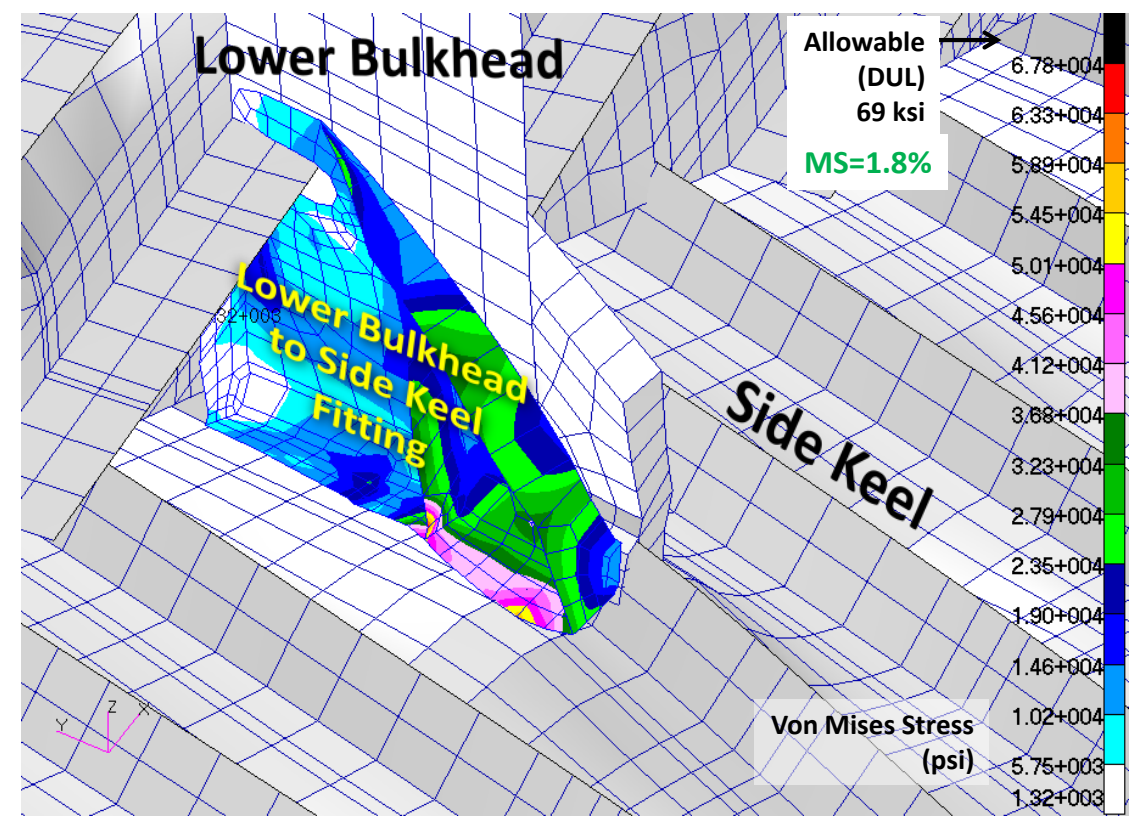

Figure 10. Von Mises Stress on Lower Bulkhead to Side Keel Fitting in the 2P DUL

\section{Detailed Structural Analyses}

In the 2-D linear detailed FEA, fine-mesh FE models were created. The mesh on the global FE model was replaced by these fine-mesh FE models at critical locations such as keyholes on the frame where high stress/strain values were expected (Figure 11). The stress/strain concentration is inherent to structures with cutouts, and the peak is usually located at the edge of a cutout. The magnitude and location of the stress/strain concentration on the frame keyhole depends on the amounts of axial load and bending moment applied to the frame. The area with the highest stress/strain concentration is usually localized at the edge of a keyhole. On this test article, there were a few keyhole locations where their maximum and minimum principal strain values exceeded the notched design values at DUL but were within the undamaged (pristine) strain design values of the composite materials. These critical keyhole locations were at the frames on the center sections of crown, upper bulkhead, and center keel. Since these principal strains did not exceed the design values of the pristine composites at DUL, and were confined to the local regions, no extra design changes were made. Unlike the acreage strain values calculated from a global FE model, which are generally required to be lower than the notched strain design values, the localized peak strains caused by the effect of stress/strain concentration in a fine mesh model are usually allowed to be higher than the notched strain design values, provided that they are still within the strain design values of an undamaged (pristine) composite at DUL. 


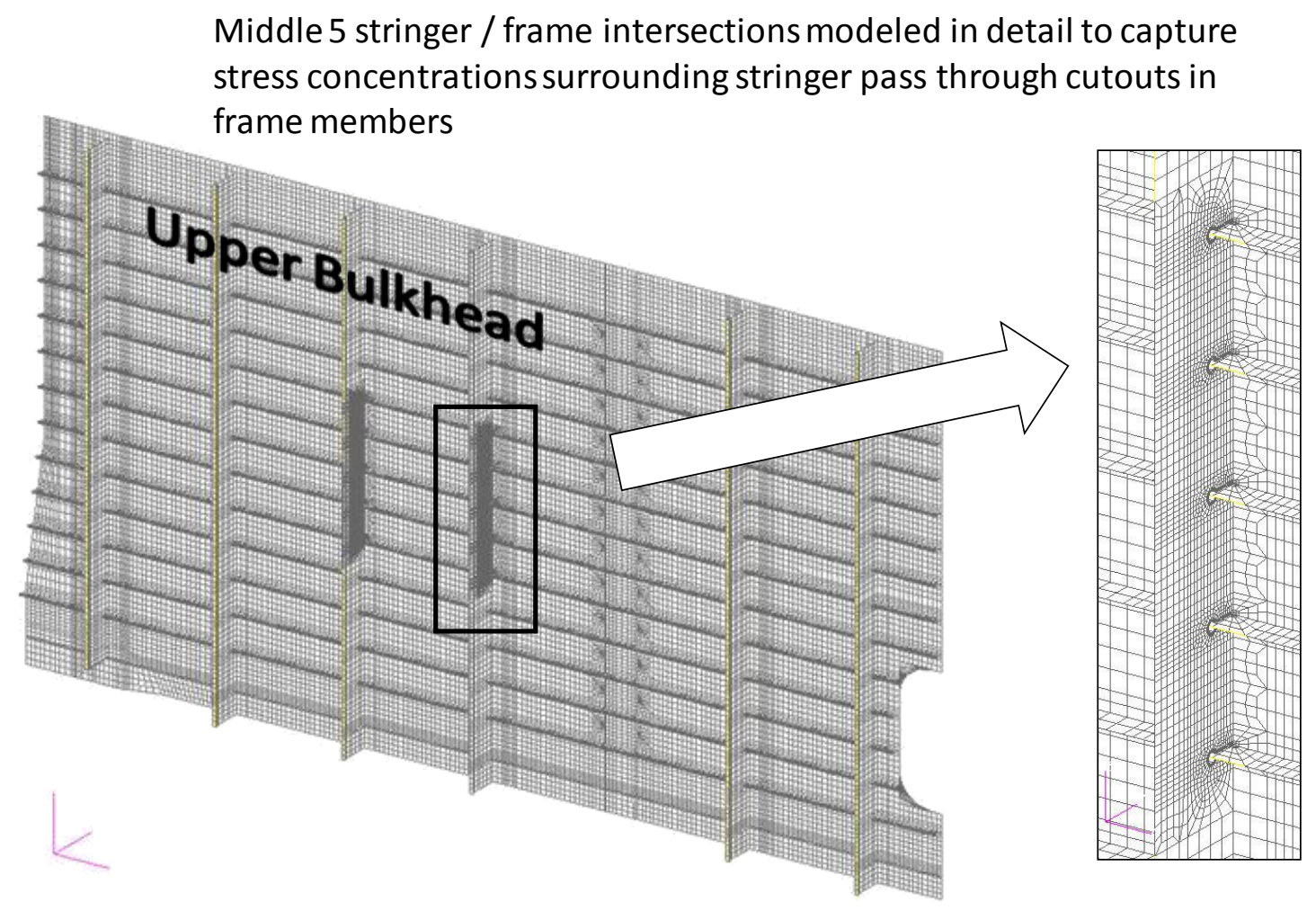

Figure 11. 2-D Detailed Fine Mesh FE Model of Frame Keyholes

The integral cap features in the pressure cube and the HWB center section test article are made by folding layers of warp-knit fabric to create a Tee-cap and skin configuration as shown for the crown panel in Figure 12. A braided fillet detail (noodle) fills the gap between the Tee-cap web, Tee-cap flange, and skin layers. During the testing of the pressure cube, an inter-laminar tension failure occurred along the fillet on the crown panel at $16 \mathrm{psi}$. As the fillet delamination spread, it was contained by the adjacent stitching, enabling the Tee-cap to continue carrying loading until the final catastrophic failure occurred at 48 psi. Post-test microscopic examination was performed on the pressure cube by sectioning the delaminated Tee-cap of the pressure cube structure. The examination revealed that the inner radiuslaminate of the Tee-cap had delaminated like an onion peel. A 3-D detail FEA of the Tee-cap from the pressure cube confirmed that high inter-laminar tensile stresses appeared along the inner radius-laminate. This type of resin failure mode was caused by the high inter-laminar tensile forces generated by the pull-off loads and rocking moments imparted on the Tee-cap by the internal pressure. 


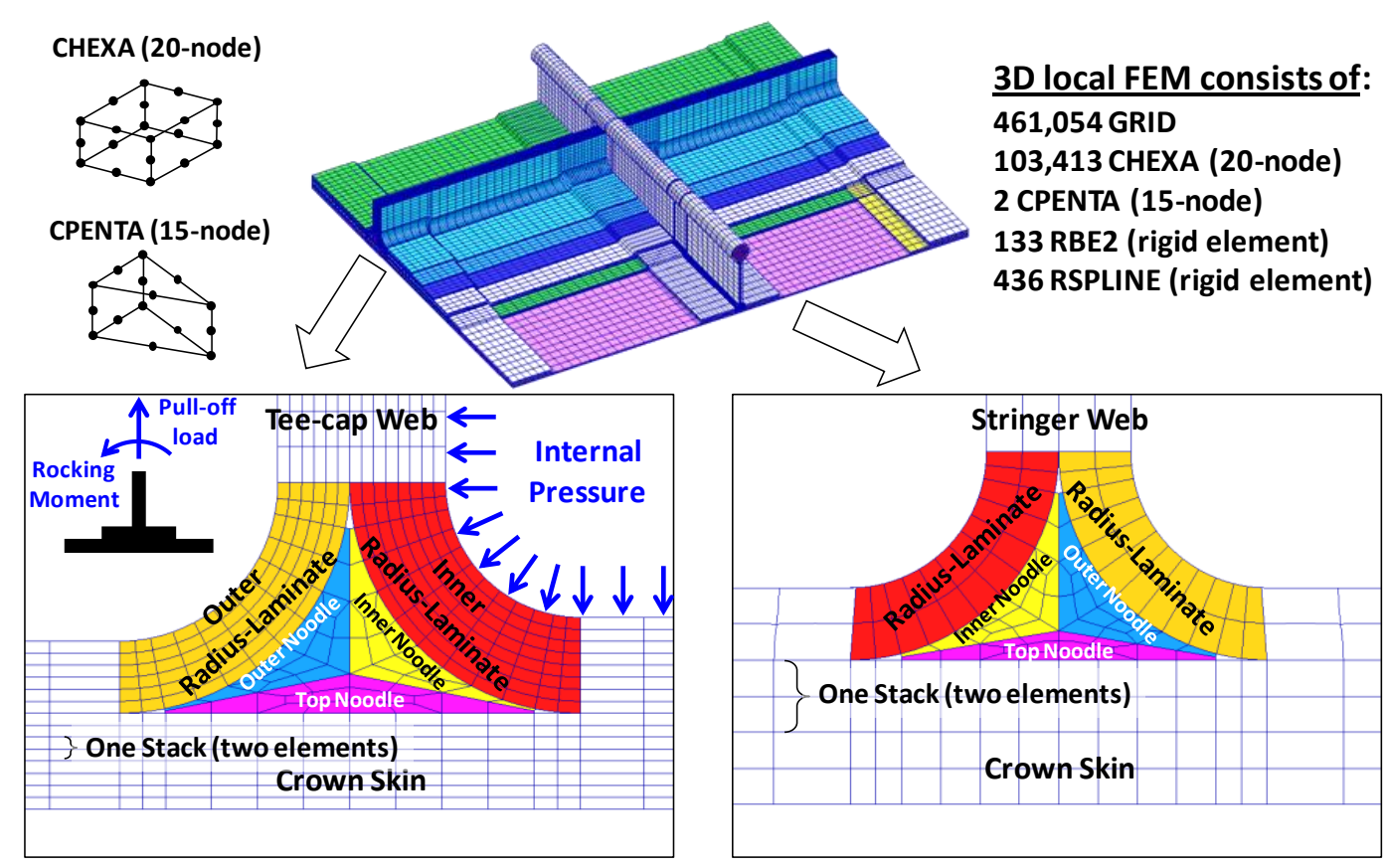

Figure 12. 3-D Detailed FEM for Inter-laminar Tensile Stress Calculations

The test article has integral cap features on the crown, floor, keel, and upper bulkhead panels, which are similar to those in the pressure cube structure. Based on the experimental results of the pressure cube test, it is reasonable to expect that similar inter-laminar resin failures will occur again. To investigate the susceptibility of the laminate interface cracking at the noodle location, a high fidelity 3-D detailed FE model (Figure 12) was built to perform inter-laminar tensile stress calculations at the most critical locations where the pull-off load and rocking moment on the Tee-cap were the highest. CPENTA and CHEXA 3-D solid elements were used in modeling the noodle and laminates of the Tee-cap, stringer, and skin on crown.

On this test article, the Tee-cap that had the highest pull-off load and rocking moment was at the location where the crown panel and upper bulkheads were connected. From the 3-D detailed FE analysis, a high inter-laminar tensile stress value (13.6 ksi) was observed on the stringer radius-laminate which is connected to the terminated-end of the Tee-cap noodle in the 2P DUL (Figure 13). This high inter-laminar tensile stress value is probably caused by the stress concentration due to the termination of Tee-cap noodle at the intersection with stringer member. Failure calculation for the interface cracking showed that resin cracking (or delamination) at the stringer radius-laminate would occur at an internal pressure of 8.7 psi due to high inter-laminar tensile stress. While this pressure loading value was lower than the 2P DUL, the area with high inter-laminar tensile stress was confined to the fillet region and captured by the stitching threads. If this interface resin cracking between stringer radiuslaminate and Tee-cap noodle occurs, this localized resin cracking will probably be contained by the surrounding stitches and the stringer and Tee-cap will still be able to carry higher load, as it did in the pressure cube test. 


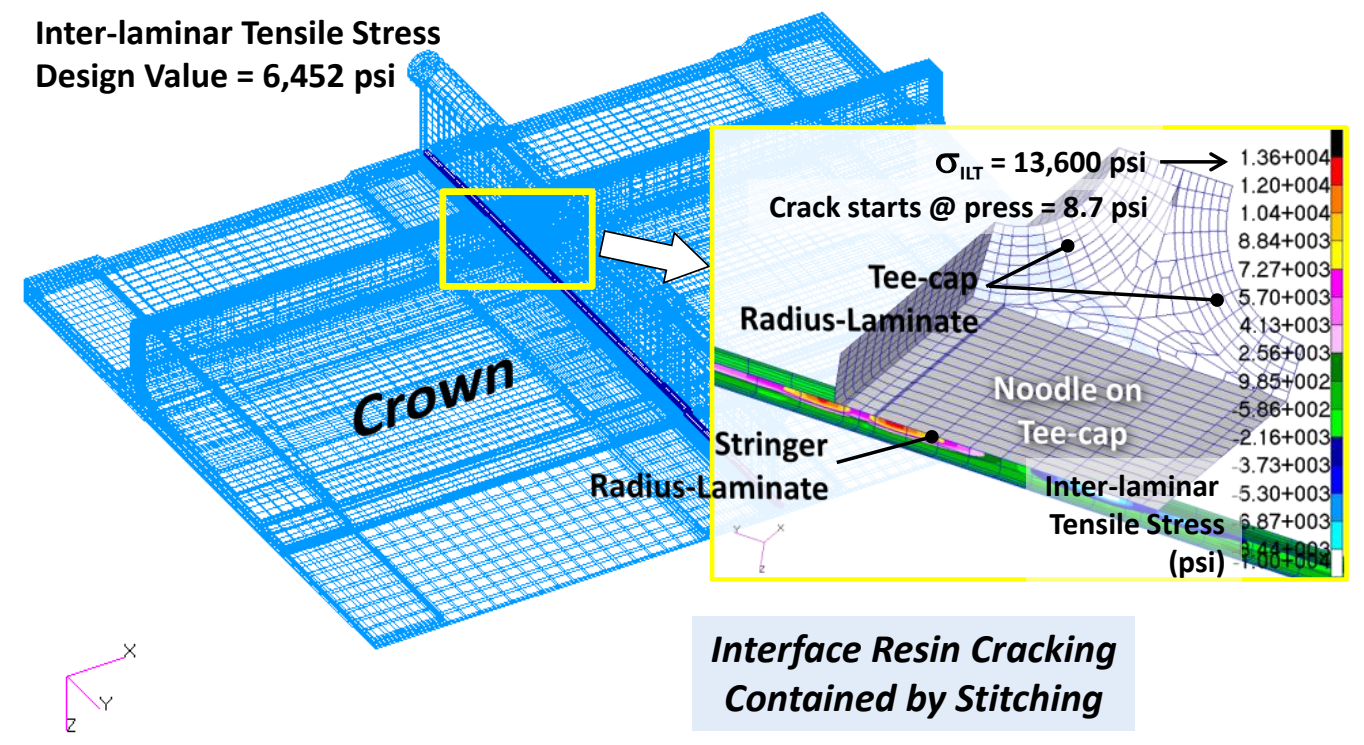

Figure 13. Inter-laminar Tensile Stress on Stringer Radius-Laminate in the 2P DUL

Another important check that was performed on the test article composite structures is the bearing/bypass interaction analysis on locations that had high bearing and bypass loads. This bearing/bypass interaction check is in addition to those typical fastener-related failure checks that were performed in the global FEA. In the test article, the critical areas that required bearing/bypass interaction analyses are located at the panel-to-panel connections, such as the frames on upper and lower bulkheads that are connected to the crown, floor, and keel panels. While loaded in internal pressure, the upper and lower bulkhead panels of the test article will bulge outward like a balloon. Consequently, high bearing and bypass loads are seen on the connecting frames of the upper and lower bulkheads to the crown, floor, and keel panels. To capture the composite bolted-hole behaviors of these frames, composite bearing/bypass interaction studies were performed on these frames at the fastener locations.

Depending on the magnitudes of bearing and bypass loads, a bolted composite may fail along its bearing or bypass loading directions. Therefore, bearing/bypass checks were performed in both bearing and bypass directions at each fastener location. The results of bearing/bypass studies on critical frames showed that their margins of safety were all positive for the DUL conditions. From the bearing/bypass check, the lowest margin of safety was $56 \%$ and was located at the upper bulkhead frame where it was connected to the crown by a metallic fitting and fasteners (Figure 14). In a typical bearing/bypass check, the calculated values of composite bypass strain $\left(\varepsilon_{\mathrm{pt}}\right)$ and composite bearing stress $\left(\mathrm{f}_{\mathrm{br}}\right)$ at a critical bolted-hole location were plotted against the bearing/bypass interaction curves. These interaction curves were created by enveloping the composite's bearing strength values $\left(\mathrm{F}_{\text {bru }}, \mathrm{F}_{\text {bry }}\right)$ and netsection strength values $\left(\varepsilon_{\mathrm{uht}}, \varepsilon_{\mathrm{uhc}}, \mathrm{F}_{\mathrm{brl}}\right)$, as shown in Figure 14. These composite strength values were determined by tests as a part of the NASA's Advanced Subsonic Technology (AST) Composite Wing program. ${ }^{[18]}$ When loaded in tension, which was the situation with the upper bulkhead frame (Figure 14), the margin of safety was calculated by comparing either the bearing stress $\left(\mathrm{f}_{\mathrm{br}}\right)$ or the principal bypass strain $\left(\varepsilon_{\mathrm{pt}}\right)$ to their failure values (MS = $\mathrm{F}_{\mathrm{brt}} / \mathrm{f}_{\mathrm{br}}-1$ or $\left.\mathrm{MS}=\varepsilon_{\mathrm{byt}} / \varepsilon_{\mathrm{pt}}-1\right)$. 


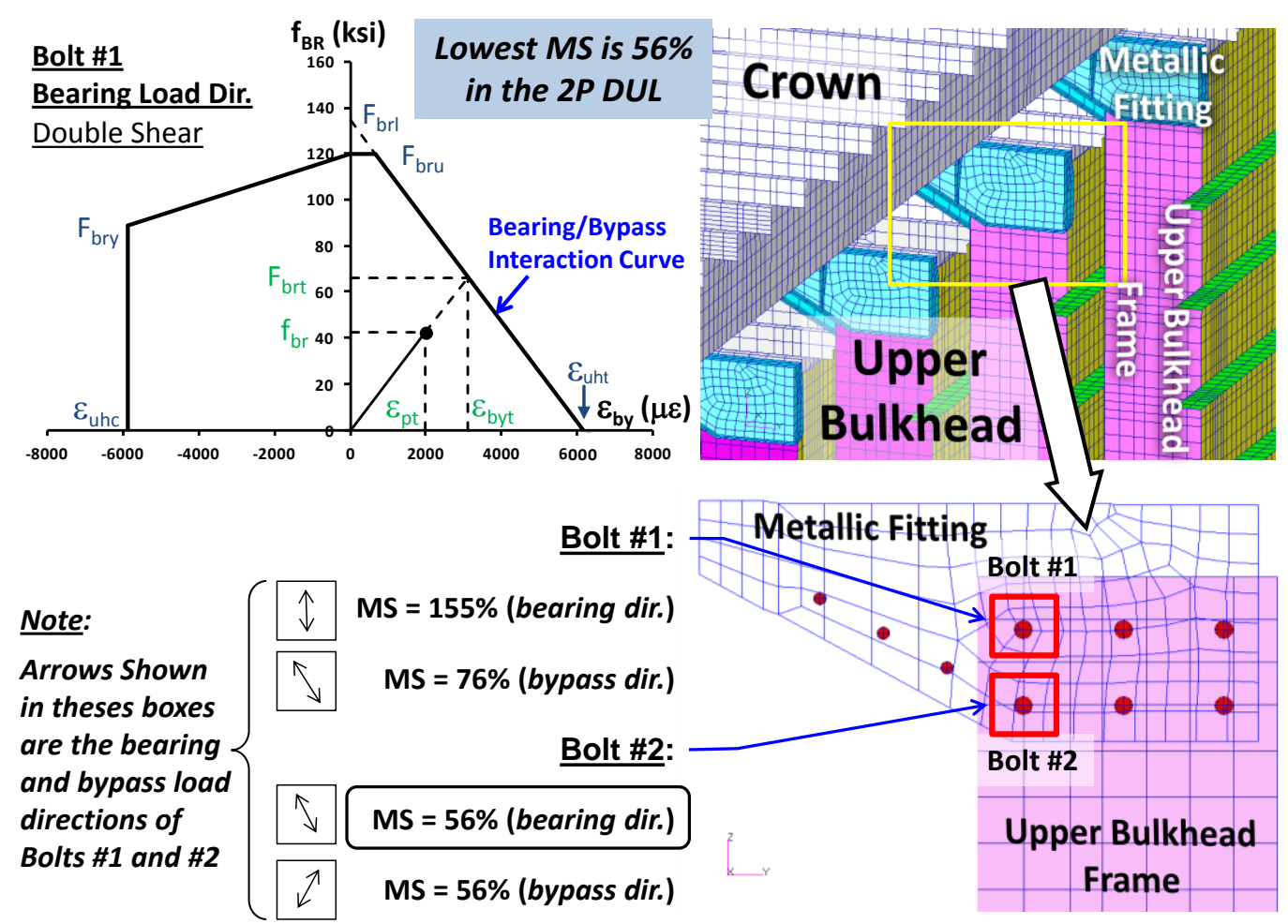

Figure 14. A Typical Interaction Curve and Bearing/Bypass Check in the Test Article

\section{Linear Structural Stability Analysis}

In the structural stability studies, linear buckling analyses were performed for the $2 \mathrm{P}$ DUL pressure condition and the maneuver (2.5-g, and -1.0-g) DLL conditions. Linear buckling analyses were not performed for the combined maneuver-and-pressure $(2.5-\mathrm{g}+1 \mathrm{P}$ and $-1.0-\mathrm{g}+1 \mathrm{P})$ loading conditions because the structural response in these cases may warrant accounting for geometrically nonlinear behavior. For the $2 \mathrm{P}$ linear buckling analysis, the first buckling mode appeared at the doubler plate on the keel splice intercostal fitting at 3.57P or $32.9 \mathrm{psi}$, which is higher than the 2P DUL (Figure 15). For the 2.5-g linear buckling analysis, the skin at the center section of crown panel would buckle at $0.347-\mathrm{g}$ up-bending load (Figure 16). For the -1.0-g linear buckling analysis, the skin of the center keel would buckle at -0.754-g down-bending load, and the skin at the center section of floor panel would buckle at -0.840-g down-bending load (Figure 17). The locations of the skins on crown, floor, and center keel that buckled were flat and had the minimum-gage skin thickness. Even though these skins would buckle at load levels less than DLL, it is probable that they will behave like a previously tested compression panel and support higher loads by entering the postbuckling stage in structural tests. A prior experiment for a compression panel showed that the skin buckled long before the frames failed, allowing the panel to support seven times the skin buckling loads. ${ }^{[9]}$ The test article's post-buckling load-carrying capabilities will ultimately be determined by the final experiments at the COLTS facility. 


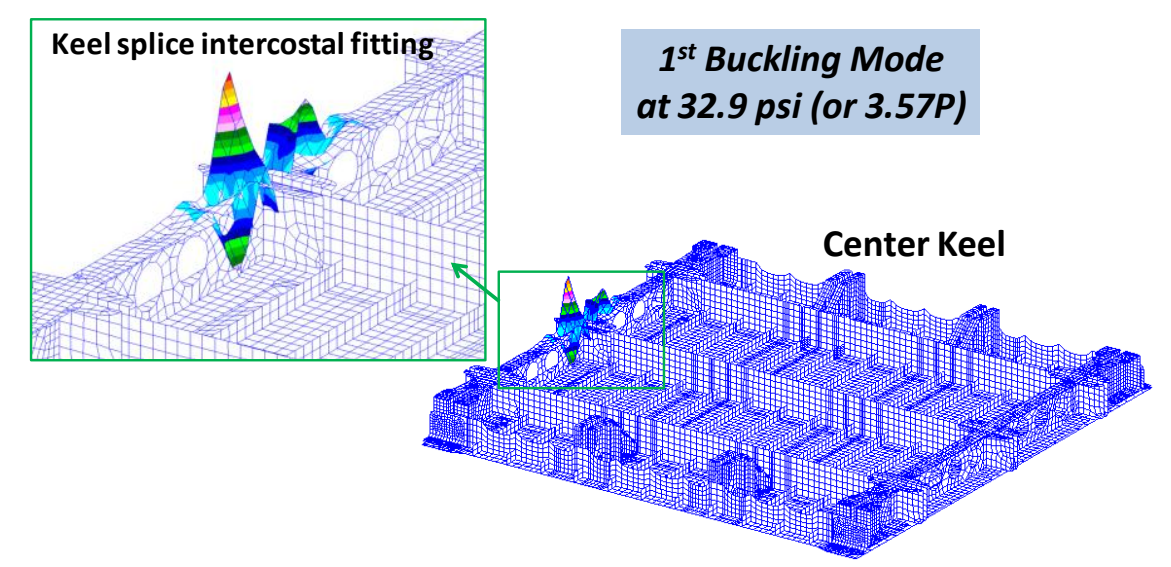

Figure 15. First Buckling Mode in the 2P Pressure Condition

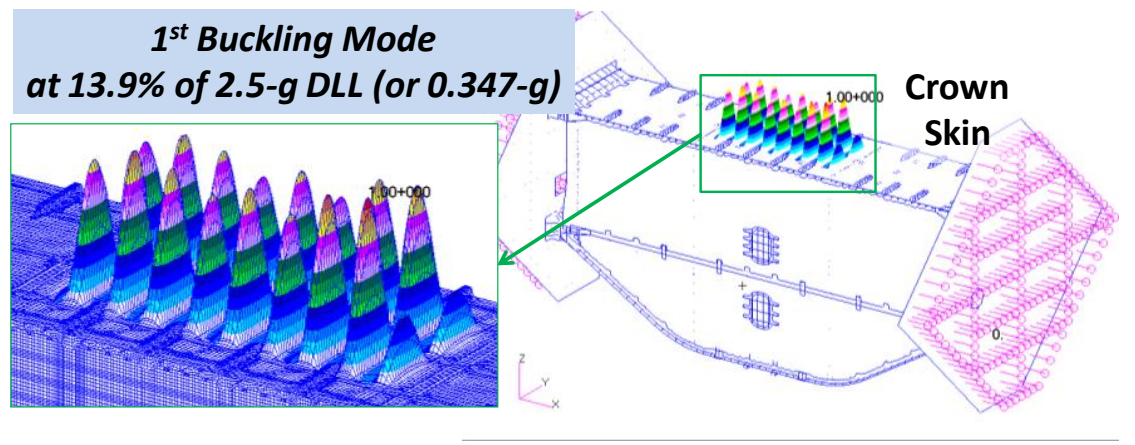

Figure 16. First Buckling Mode in the 2.5-g Maneuver Condition
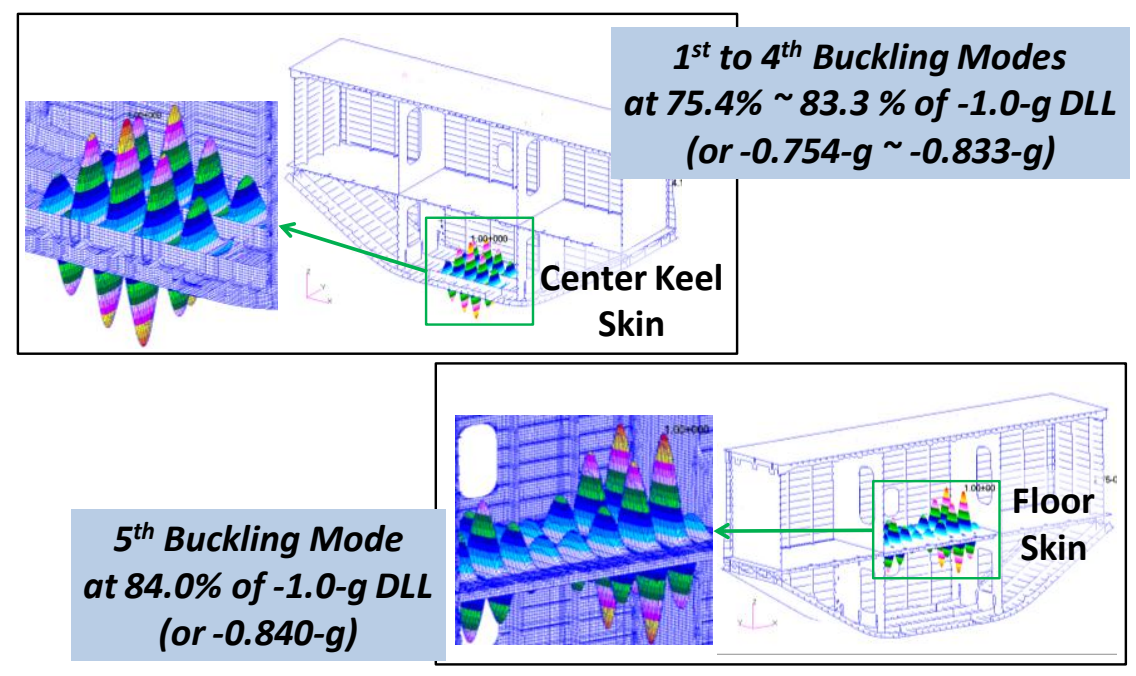

Figure 17. First Five Buckling Modes in the -1.0-g Maneuver Condition

\section{Nonlinear Analysis and Preliminary Results}

For some load cases a nonlinear structural response of the test article is expected prior to reaching the DUL. Areas where nonlinear behavior is expected include locations of large out- 
of-plane deformations of panels constrained at their boundaries, resulting in significant inplane strains. This behavior can be captured through the geometrically nonlinear analysis. Therefore, the global FE model described in Section III was adapted to perform nonlinear static analyses per NASTRAN Solution 106. ${ }^{[1]}$ While the nonlinear analysis effort is still ongoing, preliminary results for the $2 \mathrm{P}$ load are plotted in Figure 18 and compared with the previously discussed linear solution. Although the displacement patterns are similar for the linear and nonlinear solutions, the magnitudes obtained from the nonlinear solution are generally smaller. The maximum displacement identified in the center section of the upper bulkhead panel obtained from the nonlinear solution ( 0.952 inches) is approximately $13.5 \%$ smaller than the one obtained through the linear analysis (1.08 inches). Note, that the predominant in-plane reaction in the pressure-loaded flat panels within the geometrically nonlinear response regime is in-plane tension which tends to suppress out-of-plane deformations. While strain results are not discussed herein due to the preliminary stage of the nonlinear studies, smaller out-of-plane deformations typically result in lower principal strains. Consequently, for this particular load case the linear analysis can be expected to yield conservative results. Note that load cases involving maneuver loads can result in in-plane compressive loads in some sections of the structure, e.g., the crown panel can be compressed in the up-bending maneuver (2.5-g) and the keel and floor panels can be compressed in the down-bending maneuver $(-1.0-\mathrm{g})$. Compressive in-plane loads combined with pressure loads (2.5-g+1P and $-1.0-\mathrm{g}+1 \mathrm{P})$ can promote nonlinear response where out-of-plane deformations can exceed that obtained through the linear analysis, rendering linear analysis results not necessarily conservative. 

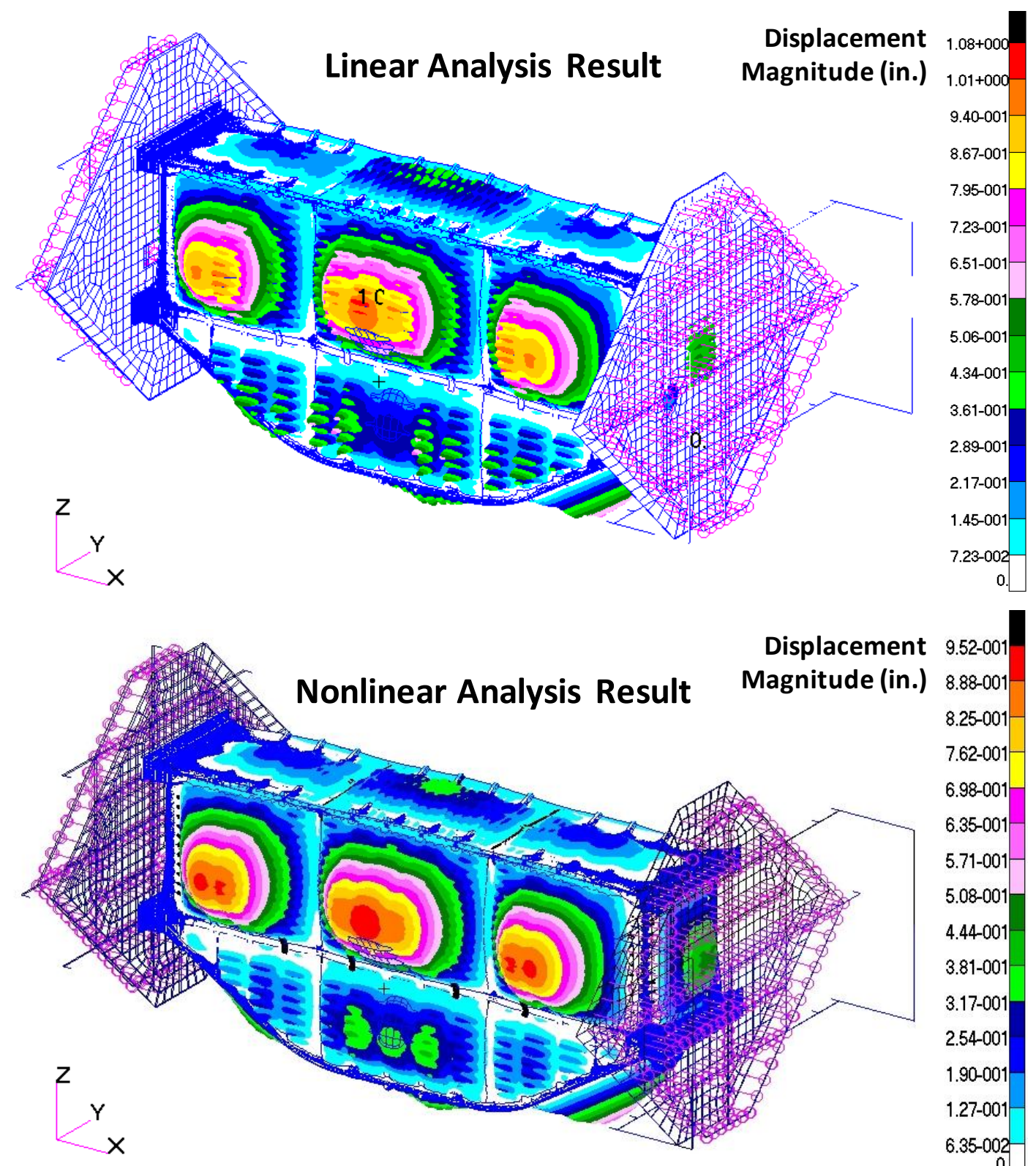

Displacement 9.52-001 Magnitude (in.) $8.88-001$ 8.25-001 7.62-001 6.98-001 6.35-001 5.71-001 5.08-001 4.44-001 3.81-001 3.17-001 2.54-001 1.90-001 1.27-001 6.35-002 0.

Figure 18. Displacement Result Comparison Between Linear and Nonlinear Analyses in the 2P DUL

\section{Conclusions}

The design and analysis of the HWB center section test article were completed under the NASA ERA Phase I study. In the global FEA, results from the linear analysis showed that all structural components of the test article had positive margins of safety in all critical DUL conditions. These structural components include composite PRSEUS panels, composite sandwich panels, metallic fittings, and fasteners. In the 2-D detailed FEA, stress/strain concentrations were observed at locations such as keyholes on the frames. At DUL, the principal strain values on some frames' keyholes were higher than the notched design values 
but still within the undamaged (pristine) design values of the composites. In a fine mesh study, it is generally acceptable for the strains to exceed the notched strain design values, as long as these strain values are still within the strain design values of an undamaged (pristine) composite at DUL. In the 3-D detailed FEA, a conservative result indicated that inter-laminar resin cracking (or delamination) at the stringer radius-laminate will occur at an internal pressure of 8.7 psi. However, since the area with high inter-laminar stress is small and confined by stitching threads, it is believed that this interface resin cracking will be contained by the surrounding stitches and the stringer and Tee-cap on the crown panel will be able to carry higher internal pressure load. In the composite bearing/bypass study, margins of safety were positive on all critical locations. In the linear buckling analyses of the $2 \mathrm{P}$ loading condition, the first buckling load was at 3.57P, which is higher than the 2P DUL. In the 2.5-g maneuver condition, the skin at the center section of crown started to buckle at $0.347-\mathrm{g}$ upbending load. In the $-1.0-\mathrm{g}$ maneuver condition, the skin at the center keel started to buckle at -0.754-g down-bending load, and the skin at the center section of floor started to buckle at -0.840 -g down bending-load. Although these buckling initiation loads are lower than the 2.5-g and -1.0-g DLL, it is probable that the crown, center keel, and floor panels will behave similarly to the previously tested compression panel in ERA Phase I study and support higher loads in the post-buckling regime.

In the geometrically nonlinear analyses, the panel deflections from the nonlinear analysis were less than the results from linear analysis in the 2P DUL. Similar to the test cube study, lower stress/strain levels were expected from nonlinear analysis on the test article in the $2 \mathrm{P}$ DUL. The nonlinear analyses of the maneuver $(2.5-\mathrm{g}$ and $-1.0-\mathrm{g})$ loading conditions will study the post-buckling behavior of the PRSEUS panels after the skin buckles in compressive loads. Again, results are expected to be similar to those of the previously analyzed and tested compression panel. Among all five critical loading conditions, the most important ones are the combined maneuver-and-pressure $2.5-\mathrm{g}+1 \mathrm{P}$ and $-1.0-\mathrm{g}+1 \mathrm{P}$ loading conditions because the compressive loads from maneuvers in the crown and keel panels, respectively, can promote early onset of buckling due to the internal pressure. The PRSEUS panel has not been tested in these combined loading conditions. The primary goal of the test article is to prove that PRSEUS components are capable of withstanding these combined maneuver-and pressure loads. Therefore, the geometrically nonlinear analyses in the combined maneuverand-pressure (2.5-g+1P and -1.0-g+1P) loading conditions are important aspects of the study. Results from these nonlinear analyses will provide critical information regarding how the test article will behave in the experiment. The analytical results in this study will guide the development of the test plan for the test article at the NASA COLTS test facility.

\section{References}

1. Jegley, D.C., and Velicki, A., "Status of Advanced Stitched Unitized Composite Aircraft Structure", 51st AIAA Sciences Meeting, Environmentally Responsible Aviation Progress I Technical Session, paper Number AIAA 2013-0410, Jan 7-10 2013, Grapevine, TX.

2. Velicki, A., and Thrash P.J., "Blended Wing Body Structural Concept Development," Aircraft Structural Design Conference, Oct 14-16 2008, Liverpool, UK. 
3. Velicki, A., and Jegley, D.C., "PRSEUS Development for the Hybrid Wing Body Aircraft," Proceedings of the AIAA Centennial of Naval Aviation Forum "100 Years of Achievement and Progress," AIAA-2011-7025, Virginia Beach, VA, 2011.

4. Velicki, A., Jegley, D.C., and Thrash P.J., "Airframe Development for the Hybrid Wing Body Aircraft," 47th AIAA Sciences Meeting, AIAA-2009-932, Jan 5-8 2009, Orlando, FL.

5. Ambur, D. A., Rouse, M., Starnes, J.H., and Shuart, M. J., "Facilities for Combined Loads Testing of Aircraft Structures to Satisfy Structural Technology Development Requirements," presented at the 5th Annual Advanced Composites Technology Conference, Seattle, WA, August 22-36, 1994.

6. NASA Phase I Final Report, "Damage Arresting Composites for Shaped Vehicles", Velicki, A., NASA/CR 2009 215932, Contract NNL07AA48C Project No. 4200208122, September 2008.

7. Jegley, D.C., Velicki, A., Hansen, D., "Structural Efficiency Of Stitched Rod-stiffened Composite Panels With Stiffener Crippling," 49th AIAA/ASME/ASCE/SHS/ASC Structures, Structural Dynamics, and Materials Conference, 7-10 April 2008, Schaumburg, IL.

8. Jegley, D.C., "Experimental Behavior of Fatigued Single Stiffener PRSEUS Specimens," NASA TM 2009-215955, Dec. 2009.

9. Yovanof, N., and Jegley, D., "Compressive Behavior of Frame-Stiffened Composite Panels," 52th AIAA Structures Dynamics and Materials Conference, paper Number AIAA-2011-1913, 5 April 2011, Denver, CO.

10. Velicki, A. and Thrash, P.J., "Advanced Structural Concept Development Using Stitched Composites," 49th AIAA/ASME/ASCE/SHS/ASC Structures, Structural Dynamics, and Materials Conference, 7-10 April 2008, Schaumburg, IL, AIAA Paper 2008-2329.

11. Velicki, A., and Thrash, P.J., "Damage Arrest Design Approach Using Stitched Composites", The Aeronautical Journal, December 2011, Volume 115, Number 1174, pages 789-795, Royal Aeronautical Society, London, UK.

12. Bergen, A., Bakuckas, J., Lovejoy, A., Jegley, D., Linton, K., Korkosz, G., Awerbuch, J., Tan, T., "Full-Scale Test and Analysis of a PRSEUS Fuselage Panel to Assess DamageContainment Features," Aircraft Airworthiness \& Sustainment Conference 2011, paper Number TP4558, 20 April 2011, San Diego, CA.

13. Lovejoy, A., Rouse, M., Linton, K., and Li, V., "Pressure Testing of a Minimum Gauge PRSEUS Panel," 52th AIAA Structures Dynamics and Materials Conference, paper Number AIAA-2011-1813, 4 April 2011, Denver, CO.

14. Yovanof, N., Baraja, J, Lovejoy, A., Gould, K., "Design, Analysis, and Testing of a PRSEUS Pressure Cube to Investigate Assembly Joints," 2012 Aircraft Airworthiness \& Sustainment Conference, paper Number TP5431, 1-5 April 2012, Baltimore, MD.

15. Li, V., and Velicki, A., "Advanced PRSEUS Structural Concept Design and Optimization", 12th AIAA/ISSMO Multidisciplinary Analysis and Optimization Conference, AIAA-2008-5840, Sept. 10-12 2008, Victoria, British Columbia, Canada.

16. Yovanof, N. P., Velicki A., and Li, V., "Advanced Structural Stability Analysis of a Nonlinear BWB-Shaped Vehicle," Proceedings of the 50th AIAA/ASME/ASCE/AHS/ASC Structures, Structural Dynamics and Materials Conference, AIAA-2009-2452, Palm Springs, CA, 2009. 
17. MD/MSC Nastran 2010 Quick Reference Guide, MSC Software Corporation, Santa Ana, CA, 2010.

18. Karal, M., "AST Composite Wing Study - Executive Summary", NASA/CR-2001210650, Prepared for NASA, Langley Research Center under Contract NAS1-20546, March 2001. 